\title{
Content distribution and protocol design issue for mobile social networks: a survey
}

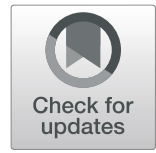

Rizwan Akhtar ${ }^{1 *}$ (D, Yan Shengua 1,2, Zhu Zhiyu', Zuhaib A. Khan ${ }^{3}$, Imran Memon ${ }^{4}$, Saeed ur Rehman ${ }^{3}$ and

Saeed Awan $^{3}$

\begin{abstract}
Mobile social network (MSN) consists of a flavor of social science and wireless communications for mobile networking. A mode to provide communication process between different nodes with similar interest's exploits MSN. Content delivery network (CDN) improves the network performance of MSN and provide quick and quite reliable applications by distributing content through some agents placed nearby the social community. MSN architecture can be modeled to provide smooth data exchange, sharing, and delivery of packets among different nodes. The fundamental working principle of architectural and protocol design is to increase the overall efficiency of the MSN in terms of end-to-end content delivering ratio, decreasing delay, and the removal of the congestion before it happens. Efficient content delivery in MSN benefits includes reduced latency for end users, less origin server load, and increased throughput. The unique characteristics of MSN belonging to social relations provide a platform for a variety of architecture and protocol design issues. This manuscript provides a comprehensive survey of MSN, particularly with respect to content distribution and designing of different protocols approaches. At first, some routing protocols and their comparison is given. Next, several approaches toward content distributions in MSN are presented. In the end, comparisons of the various methods that are based on centralized distribution approaches are given.
\end{abstract}

Keywords: Mobile social networks, Network performance, Content delivery ratio, Social relationship, Routing protocol

\section{Introduction}

Mobile social network (MSN) is considered as the system which has the capability to generate different kinds of content delivery related applications by the involvement of the social relationships of the social community of the users of the mobile systems. MSN is not only aimed to define the act of social entities; it can help in the understanding of different kind of relations between them as well. Practically, a social network is kind of a structure of entities (e.g., individuals, organizations, and systems) that have a connection with each other by the source of one or can be more interdependencies [1]. The techniques of social networking are being utilized in the domain of communication and information technologies for the purpose of providing an efficient way of content exchange, and also delivery services [2].

\footnotetext{
* Correspondence: rizwanakhtarpk@gmail.com

${ }^{1}$ School of Electronics and Information, Jiangsu University of Science and

Technology, Zhenjiang, People's Republic of China

Full list of author information is available at the end of the article
}

Efficient content delivery and content distribution are the major issues in the MSN because they have sparse connectivity having a limited amount of mobile node resources. For the aim of efficient and effective content distribution and efficient end-to-end, some techniques and schemes are desired in the MSN. The information concerns with social patterns are regarded as a plus benefit for the opportunistic contacts which is used to measure as capacity available to update content [3]. However, such added capacity is helpful for the betterment of the performance of a network in content distribution. The issues related to content delivery and content distribution of MSN for improving the performance is solved by our given approaches.

Content delivery networks (CDNs) can create a trusted overlay for the networks that have the ability to offer high performance that is also related to the delivery of Web content, rich multimedia, and static data by a distribution of the contents among agents that are present closer to the mobile clients [4-106]. A CDN advantage is to reduce original server computational power, latency, and increased 
throughput. A method is to construct virtual networking that can stand at the top of a transport layer or produce generic IP layer for the cause of adding functionality that provides flexibility to IP networks. Such an overlay network provides traffic control, flexibility, and also resource management having the advantages of extending across a platform of heterogeneous network excluding prominent changes in the underlying technology. MSN is one kind of a generic IP network that requires CDNs for setting up of overlay network in order to improve overall networking performance and thus offer reliable and fast application services. CDNs help MSN for content distribution between the nodes as well. A CDN is one kind of a system or simply an agent containing copies of sharing content that is placed at different locations of MSN for the aim of maximizing bandwidth to get access to the content from different mobile nodes/clients placed thoroughly in a given network. A mobile client can communicate to access different contents from nearby located agents.

CDNS can also be utilized for efficient content distribution across the MSN. The new challenge of distribution of the content is major focused of CDNs. One general solution can be given by the optimization of the path between the edge servers and the source [5]. The significant issue which needs to be solved is to find few potential solutions for a cache of the existing dynamic contents and applications is much needed that can lead the edge servers for distributing widely to enhance the experience of the user. In MSN, one social node can act as a proxy server. One powerful resource node encounters with the main server for caching content and then distributes the contents throughout the MSN.

MSNs routing mostly suffers from the facts that there does not exist a routing path between communication end-to-end points. Different routing protocols based on ICN using opportunistically forwarding and a predictionbased scheme as well are proposed for MSN.

Labeling is the routing scheme that is proposed for MSN exploiting different routing protocols. In such an approach, a source social node transmits a message for sharing nodes that possess the similar label as for the destination social node. Several MSN routing protocols are also based on the prediction schemes. Several existing MSN routing protocols are also investigated. Socially based protocols can be a better choice for the wireless-based social networking infrastructure that can recognize similar social connected nodes, and that is to exploit context information [6] such as sharing interests or community affiliation. Socially related based routing is specifically suitable for providing a solution to the opportunistic network having social factors such as pocket switched [7], and the other is mobile peer-to-peer networking [8].

Opportunistic networks [12] are defined by unpredictable, disconnection, partitions, and also unstable topology for example disconnected delay tolerant MANET called DDMT [14], a delay tolerant network called DTN [13]. In the network, mostly mobile nodes are sparsely connected due to their mobility in nature; therefore, there is no fixed infrastructure between the source and the destination nodes. When people are in constant mobility, such characteristics are usually seen in human societies. Opportunistic networks can support suitable infrastructure for creation of MSN [15]. The intermediate mobile node is used to exploit any future contact opportunity by other nodes for the transfer of contents nearby to the destination [17]. Different mobile nodes participate by taking independent decisions for forwarding if satisfying the probability estimation of the encountering the destination node [18]. Packet forwarding and routing are the major focus in opportunistic networking because of the intermittent connectivity and long duration disconnection [16]. Mobile assisted based routing is used as a special kind of routing scheme and termed as a store, carry and forward.

Presently, many surveys are addressed on MSN and can be cited in the literature. The classification of survey works correspond to the media and host layers are divided into MSN network later and MSN software system later as presented in Table 1.

However, it is observed via Table 1 that an extensive survey in mobile networks considering an overall design and development of protocol design and architectures with the perspective of MSN and mobile computing is still lacking. Hence, it would be quite interesting for researchers, developers, and service providers to exploit issues related to MSNs.

The main contributions of our work are highlighted as follows:

- Some practical scenarios of applications by designing of new protocols for MSN are reviewed.

- The main focus is on understanding social behavior and transmission interactions among different present nodes in a system that give an insight and also highlight the design-related issues of socialbased protocols for routing.

- New sources of social relations are introduced and a thorough comparison is provided in detail. Different metrics and techniques need to identify the attributes of social behavior and its detailed review is given.

- To improve the overall performance of the variety of protocols and different strategies in social-based approaches for routing algorithms, an investigation is done.

- We focus on content distribution issue, technical solution, and differently available mobility trace for simulation purpose of different routing protocols. 
Table 1 Taxonomy of the current survey works of MSN

\begin{tabular}{|c|c|c|c|c|c|c|c|c|c|c|c|c|c|}
\hline \multirow[t]{2}{*}{ Subjects } & & & \multicolumn{11}{|c|}{ Survey works of MSN } \\
\hline & & & [67] & {$[68]$} & [69] & [70] & {$[71]$} & {$[72]$} & [73] & [74] & [75] & [76] & [77] \\
\hline \multirow{6}{*}{$\begin{array}{l}\text { MSN software } \\
\text { system layer }\end{array}$} & \multicolumn{13}{|c|}{ MSN software system architecture } \\
\hline & \multirow{2}{*}{$\begin{array}{l}\text { Applications } \\
\text { and services }\end{array}$} & Applications & $\checkmark$ & $\checkmark$ & & & $\checkmark$ & & & & & & \\
\hline & & Web-based services & & & $\checkmark$ & & & & & $\checkmark$ & & & \\
\hline & \multirow[t]{3}{*}{ Methods } & $\begin{array}{l}\text { Mobile software platforms_commercial and } \\
\text { based on Internet }\end{array}$ & & & & $\checkmark$ & & & & & & & \\
\hline & & $\begin{array}{l}\text { Mobile software platforms—based on hybrid } \\
\text { network for distributed computing/application } \\
\text { development }\end{array}$ & & & & $\checkmark$ & & & & & & & $\checkmark$ \\
\hline & & Mobile operating systems & & & & & & $\checkmark$ & & & & & \\
\hline \multirow[t]{4}{*}{ MSN network layer } & \multicolumn{2}{|c|}{ Wireless access infrastructures } & $\checkmark$ & $\checkmark$ & & & & & & & $\checkmark$ & $\checkmark$ & \\
\hline & \multicolumn{2}{|c|}{ Middleware designs for network services } & & & & & & & $\checkmark$ & $\checkmark$ & & $\checkmark$ & $\checkmark$ \\
\hline & \multicolumn{2}{|c|}{ Protocol designs } & $\checkmark$ & $\checkmark$ & & & & & & & $\checkmark$ & & $\checkmark$ \\
\hline & \multicolumn{2}{|c|}{ MSN network architectures } & & $\checkmark$ & & & & & & & & & $\checkmark$ \\
\hline MSN transport layer & \multicolumn{2}{|c|}{ Content distribution } & $\checkmark$ & & & & $\checkmark$ & & & & & $\checkmark$ & \\
\hline
\end{tabular}

- The classification of recent social-aware protocols for routing in different sections, their detail analysis, and discussion is presented in a systematic way.

This survey paper addresses the detail about socialbased protocols routing for MSN. The survey provides a useful discussion on the issues highlighted in relevancy to content distribution for MSN. The organization of the survey paper is as follows: Section 2 provides a detail discussion about the components and types of MSN. Section 3 details the design of different protocols for social networking. Section 4 is composed of social-based routing protocols. Section 5 presents content distribution approaches in MSN. Section 6 provides the performances of MSN routing protocols. Finally, Section 7 provides an important discussion.

\section{Essentials of MSN}

In order to achieve better QoS, different social aware strategies are exploited in a scenario where different number of users act as a mobile node for communication with each other and sharing different centric information to each other for MSN which acts as a kind of heterogeneous network. The analysis of structure and social ties among different mobile nodes is done to improve the overall efficiency of sharing information in MSN which is termed as user-centric connected network works wirelessly to provide communication. In MSN, the mobile transmits data and provides constant feedback at the same instance to improve the application and services [9]. The feedback provided by different users is merely dependent on social interaction with different available mobile users.
The better way to analyze the social relationships between different mobile nodes/users is done by utilizing mobility as an additional approach of information. This approach will construct an important platform to differentiate between different available MSN services and applications with classical services for social networking. The common practice of sharing interests among the social relationships are defined by social network metrics that are being utilized, that can provide the basis for interdependencies and to explore concept of social relations within the MSN.

\subsection{Kinds of MSN}

In order to fulfill the conditions such as data exchange, sharing contents, and delivery services, the concept of MSN is revolutionized. MSN can further be classified into two types. One is web-based MSN, whereas the second is termed as decentralized MSN [19].

\subsubsection{Centralized MSN}

Centralized MSN focuses upon social network applications and services that is a very common example and few applications are for instance Facebook and Twitter, etc. The website can be used as mobile portal websites for getting information with the aid of mobile devices [20]. Using wireless connectivity, different mobile users can communicate with each other using web-based services by accessing the Internet. Many forms of web-based MSN services accommodate different mobile users as depicted in Fig. 1. For example, Facebook and Apple iPhone App. [21] are mobile applications that allow mobile users to exchange information with each other via web-based. In order to locate the exact information's location and some particularly interesting mobile node, MSN utilizes the context-aware 


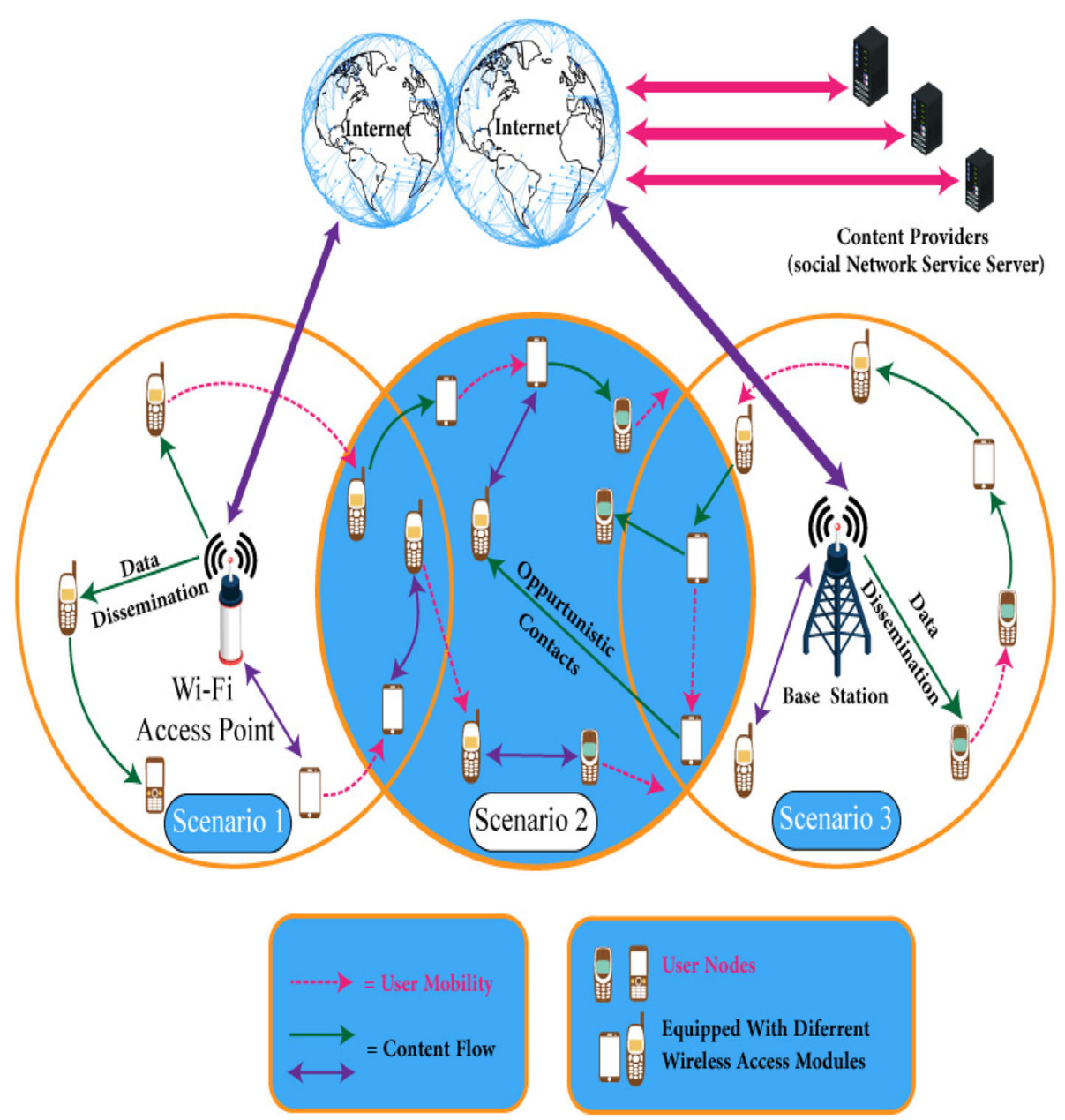

Fig. 1 Web-based MSN

information that is linked with online social networking. Google Latitude [22] is the social kind of approach that works as a web-based for socially aware users services and applications which assists different mobile users to search for a location of a particular node, interested to share its current location.

\subsubsection{Decentralized MSN}

In this particular category of MSN, different users make a social community used to disseminate different contents between them but without having a link with a server that is centralized. When mobile users can share and exchange content freely within a network, such connectivity is defined as the opportunistic contacts. In this kind, contents are shared from the source to all connected users that can communicate with each other by sharing their social and common interests. By sharing such contents, it creates a social community to disseminate different contents among mobile users
[23]. For an instant, EyeVibe [24] chat and video sharing group of a mobile system where all associated friends transfer videos and chat within the social mobile community.

\subsection{Components}

MSN is divided into three components: (1) network infrastructures, (2) mobile users, and (3) content providers, shown in Fig. 2.

\subsubsection{Infrastructures}

To transfer a transparent data from the source: content provider to the destination node as a mobile user, infrastructure plays a vital role for the network. The two basic kinds of network architectures are termed as centralized and opportunistic networking architectures respectively. For instance, a centralized network works like a Wi-Fi network, whereas cellular network mostly lies in a category of network operators, which could be different or same as content providers. Whereas, 


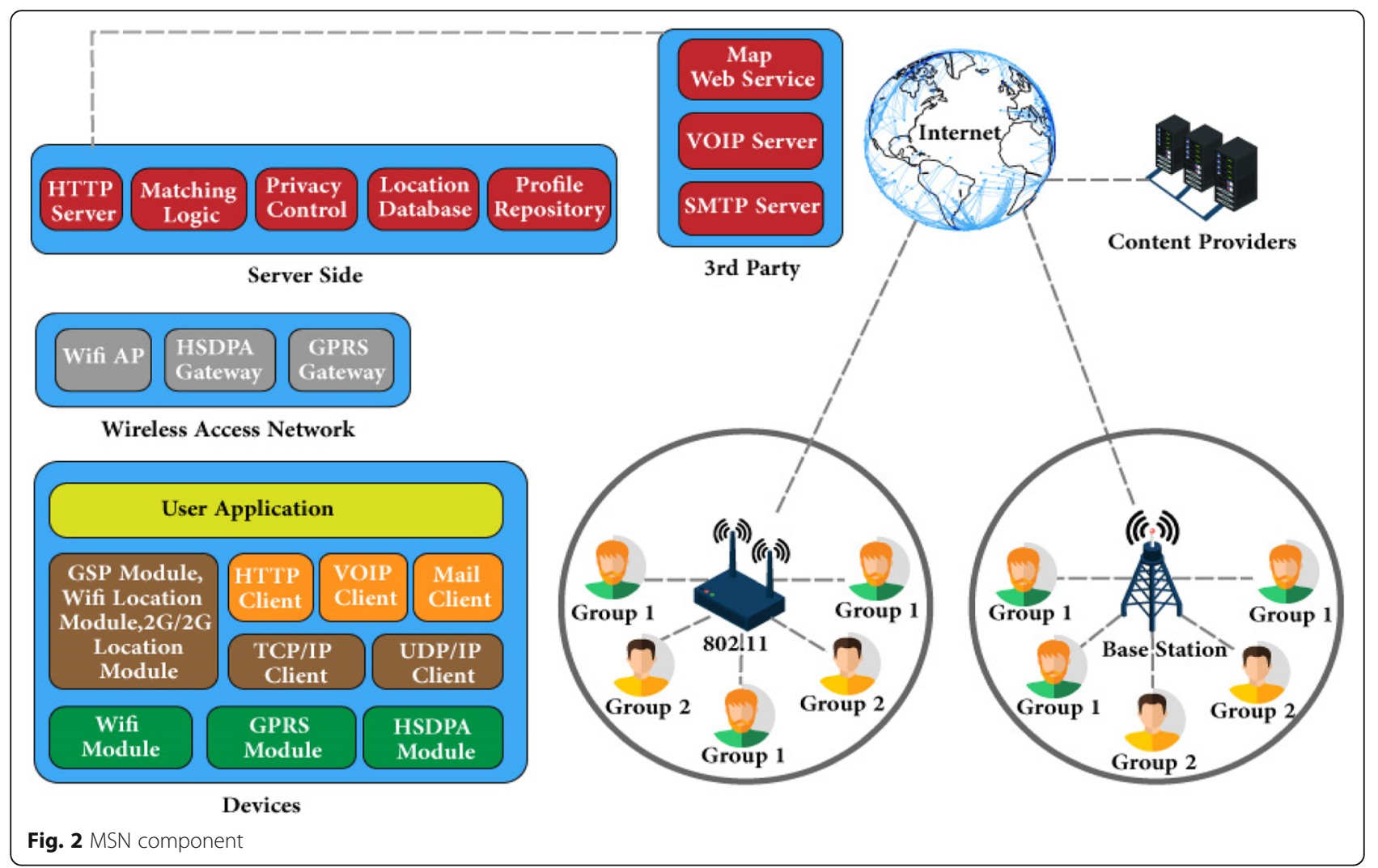

opportunistic network act as an ad-hoc network. Delay tolerant networks are basically utilized for sharing of data whenever there is an absence of the centralized network architecture as shown in Table 2.

\subsubsection{Content providers}

Mostly content providers work as a fixed, and centralized dedicated server, for instance, a web-based for news MSN server that is interlinked via the Internet. Using network infrastructure, it can also insert contents into a bunch of groups of different mobile users.

\subsubsection{Mobile unit}

Exploiting wireless access helps multiple mobile devices such as different mobile phone devices, and PDAs possessing different network interfaces. There are many network interfaces that can be used as a medium such as

Table 2 Various architectures in MSN

\begin{tabular}{|c|c|c|c|}
\hline Approach & Example & Description & Features \\
\hline $\begin{array}{l}\text { Recommendation } \\
\text { system based }\end{array}$ & $\begin{array}{l}\text { Contextualized } \\
\text { recommendation [26] } \\
\text { Social fusion [67] }\end{array}$ & $\begin{array}{l}\text { Evaluates a set of social condition and context-aware } \\
\text { actions, and to prove whether or not the conditions } \\
\text { have been logically verified for both logically verified } \\
\text { for both individual and groups of MSN users }\end{array}$ & $\begin{array}{l}\text { Focus on analyzing and discovering } \\
\text { the social relationships between users } \\
\text { Fuse the data streams from mobile users, } \\
\text { social networks and sensors }\end{array}$ \\
\hline $\begin{array}{l}\text { Social } \\
\text { identity } \\
\text { based }\end{array}$ & Whoz That for [66] & Supports increasingly complex MSN applications & $\begin{array}{l}\text { Online social identities with environment } \\
\text { adaptive ecosystem }\end{array}$ \\
\hline $\begin{array}{l}\text { Proximity } \\
\text { based }\end{array}$ & G2G [68] & $\begin{array}{l}\text { Provides a location-awareness MSN platform for } \\
\text { personalized recommender systems and gaming }\end{array}$ & $\begin{array}{l}\text { Collection of geographic-proximity } \\
\text { information about GSM cells } \\
\text { Detect preferences of nearby friends }\end{array}$ \\
\hline $\begin{array}{l}\text { Architectural } \\
\text { system } \\
\text { based }\end{array}$ & $\begin{array}{l}\text { Agent-based system } \\
\text { architecture [63] } \\
\text { Multidimensional } \\
\text { social network } \\
\text { architecture [58] }\end{array}$ & $\begin{array}{l}\text { Provides system-level approaches to effectively collect, } \\
\text { process, and utilize contextual data from a different } \\
\text { source, and facilitate development and the development } \\
\text { of context-aware MSN applications }\end{array}$ & $\begin{array}{l}\text { Based on open interfaces between social } \\
\text { networking platforms } \\
\text { Generic models to deploy different specific } \\
\text { context-aware schemes }\end{array}$ \\
\hline
\end{tabular}


Wi-Fi, Bluetooth, and cellular network depending upon the suitability. A different connected mobile user receives and relays data to the content providers at the same instant.

Different messages, packets, or collection of messages, in MSN, can have a flag that is composed of kinds of alerts, routing information, and updates. There are different kinds of content dissemination schemes such as unicast, multicast, or broadcast with respect to different types of services being utilized. The data can be shared both ways like unidirectional or bidirectional depending on the different set of rules, protocols, social analysis, and the metrics defined to disseminate contents among connected mobile users.

\section{Protocol design for social networks}

Using opportunistic forwarding results in lowering the resource consumption and as well the computational complexity. It also affects the prediction-based methods; in order to cope with it, routing exploiting social relationship is proposed. These relationships are used in different kinds. For instance, a protocol utilizing a number of common neighbors' node between encounter node toward the destination node for determining the next carrier for the message. As work colleagues mostly spend time together, so the specific routing protocol can be used by the people at different places such as at work to forward a message. These categories of routing are also used in mobile social networks. The usage of MSN has a great impact in terms of reducing resources consumption, as only relevant contents are shares among concerned nodes/destination. Moreover, MSN help in achieving low computational complexity since there is no urge for the calculation of the probability of node transmission based on contact history as shown in Table 3.

\subsection{Wireless graph}

Routing solutions depend on the existence of a wireless connection between users. These connections are mostly not persistent in the time in the networks of interest. Such networks are sparse and also topologies can change frequently.

The wireless graph is generally undirected dynamic graph having an edge between the nodes showing the link present in both directions. The information regarding the quality of the link may not be known, but the nodes are just within range of communication so that the channel can support communication at a low rate. A value of 1 shows the presence of a link from the connectivity matrix $G(T E)$ and 0 otherwise. Whenever a neighboring mobile node moves out or in of communication range, the matrix changes in the wireless graph. There exists a lot of research literature that is trying to address the problem relating to routing schemes in the social network by proposing different routing solutions. Three famous benchmark forwarding schemes have been used for the purpose of performance comparisons by almost all the recently developed protocols. The protocols that are very famous while using the information on the domain of wireless graph for forwarding messages are Epidemic, PRoPHET Spray, and Wait.

\subsection{Contact graph}

The contact graph protocols clearly process over the underlying given wireless graph. The knowledge that is available to the routing protocols increases, the overall network performances improve by lowering the average delay by increasing the delivery ratio. The new algorithms proposed by Jain et al. range from very simple like the first contact, that forwards the information to the first mobile user encountered, to the totally formulated from the linear program having information related

Table 3 Social metrics

\begin{tabular}{|c|c|}
\hline Social metrics & Description \\
\hline $\begin{array}{l}\text { Betweenness } \\
\text { centrality [69] }\end{array}$ & Indicates the bridge node or edge between two adjacent nodes or clusters \\
\hline Social ties [70] & $\begin{array}{l}\text { Meaningful social relationships characterized by a combination of the amount of the amount } \\
\text { of time and social homogeneity }\end{array}$ \\
\hline $\begin{array}{l}\text { Closeness } \\
\text { centrality [71] }\end{array}$ & Indicates the node which has the shortest path to all other nodes \\
\hline Social neighbors [72] & The set of nodes with which a host is related through special social \\
\hline Degree centrality [73] & Indicates the number of connection (direct or indirect) to other nodes in the network \\
\hline Communities [74] & A clustering of entities that are closely linked to each other \\
\hline Similarity [75] & Indicates the grouping of nodes depending upon common contacts or interest \\
\hline Edge expansion [76] & The "worst case" exit capacity from a set of nodes, in proportion to its downlink updates traffic \\
\hline Tie strength [77] & $\begin{array}{l}\text { Indicates the characteristics (i.e., strength) of a link between two nodes (e.g., using frequency } \\
\text { and duration of an encounter) }\end{array}$ \\
\hline
\end{tabular}


to a wireless graph of each time epoch, traffic demand of each node, and also queue occupied [66]. In practice, fully global knowledge related to the wireless graph is not sometimes real and the protocols given here do not support deterministic message for the future connectivity. The contact graph is useful for the prediction of such future encounters.

The contact graph can be calculated by aggregating statistics generated from the position of the dynamic wireless graph. The following are two purposes that are set by the contact graph.

(1) From the statistics, it can predict that future encounters using wireless graph by considering the mobility process is stationary and ergodic.

(2) Can decrease the amount of processed and stored information by nodes. There is no need for the node to store a snapshot by aggregating of the network at every past time epoch. Using contact graph entries lies in the connectivity's matrix $G$ (contacts) are not binary as compared to the wireless graph. The edge weight is between 1 and 0 .

The famous protocols that are using the information about the contact graph are PRoPHET, RAPID, and MaxProp to make routing decisions.

\subsection{Social graph}

A lot of literature available in research papers shows that the model design for the random mobility is not a better choice sometimes and users influenced by their mobility pattern exploiting the social-based relation or the attraction to the physical places which have the special meaning corresponding to their social behavior. Routing approaches that are using social graph contribute to performance improvement in the DTN routing schemes which are not explicitly social. Conti and Kumar identified two social levels regarding the opportunistic environment: one is virtual social networks and the other is electronic social networks [25]. Links social and in the network of an electronic relay on the physical properties of the network.

From the graph definition, the electronic social network is defined on the basis of the analysis of the contact graph. The virtual social graph is considered as an overlay network from which information for an interpersonal relationship of the mobile nodes are gained from such level included in social graph categories any protocol that uses content extracted from a social graph.

A social layer can be generated from the shared context that is based upon the user's relationships available for the network designer. The social graph definition can be presented with respect to the electronic and virtual social networks [25].

On the basis of information, social-based routing schemes can make forwarding decisions by using social graph. Social relationships come into being because of repeated contact and also from the interpersonal relationship that exists. A physical link that is not available at every instance of time, but future contact is related to the user's interpersonal relationships. Such social component hierarchal structure can be developed through shared interests, repeated contact, geographic preferences, and also by the external influences. Social-based routing protocols leverage the social relationships that are based on these commonalities at the virtual social network layer.

The integration of two different communication and social layers presented in [26] is aiming to increase routing robustness handed to social link. The communication layer consists of the links between devices and thus the social layer is created by equipment owners. History-based opportunistic routing ( $\mathrm{HiBOp})$ is forwarding protocols that consider mobility along with the context information related to virtual-based social layer to build such kind of a social graph that can predict future encounter connections.

\section{Social-based routing protocols}

This section discusses the evolution of DTNs routing protocols, and also highlights the applications of social networking theory to wireless communication systems. Previous surveys and tutorials focused on purely defining DTN architecture and discussing routing solutions shown in Tables 4 and 5. Different forwarding methods have advantages over one another in term of delivery ratio, overhead ratio, average latency, and computational complexity. For an instant, an opportunistic forward method has a probability of content delivery ratio, while prediction-based scheme offers less resource consumption. Like information-centric networks (ICN), MSN routing also suffers because of the absence of the routing channel that exists in the communication end-points mostly. Hence, ICNs routing schemes that depend on opportunistically forwarding methods and also prediction-based schemes had been proposed.

Routing method depends on three distinct graphs. The dynamic wireless graphs are created on every available link in the given time of the communication. Secondly, a contact graph which is calculated by the aggregation of past the wireless links and finally the social graph which is formed by interpersonal social relationships. Now, we discuss the detail of social-based routing protocols.

\subsection{Epidemic}

The Epidemic is a protocol [27] that is based on the broadcasting of messages. The user's node freely sends and receives messages to each other until the message reached to define a maximum number of hop counts. The message is not exchanged if there is already a copy that exists in the buffer of the host. The Epidemic has shown a good content delivery ratio, but its disadvantage is high overhead because of a large number of message copies during the flooding the network. Even though the 
Table 4 Social-based routing protocols

\begin{tabular}{|c|c|c|c|c|c|}
\hline Publication & Motivation & Main idea & $\begin{array}{l}\text { Social } \\
\text { characteristics }\end{array}$ & $\begin{array}{l}\text { Optimization } \\
\text { strategies }\end{array}$ & Simulation results \\
\hline $\begin{array}{l}\text { Socially } \\
\text { based } \\
\text { routing [78] }\end{array}$ & $\begin{array}{l}\text { Resolving the contradiction } \\
\text { that conserving limited } \\
\text { resources and achieving } \\
\text { efficient data transmission }\end{array}$ & $\begin{array}{l}\text { Present and future nodes contact } \\
\text { and buffer space are known ahead } \\
\text { of time; such knowledge is } \\
\text { exploited to increase the } \\
\text { opportunity of reaching } \\
\text { destinations }\end{array}$ & Centrality & $\begin{array}{l}\text { Controlled message } \\
\text { replication (number } \\
\text { limited), simple } \\
\text { buffer mechanism }\end{array}$ & $\begin{array}{l}\text { Reduces the number } \\
\text { of transmissions, while } \\
\text { keeping the same or } \\
\text { higher delivery ratio }\end{array}$ \\
\hline Giveaiet [79] & $\begin{array}{l}\text { Selfish nodes only torward } \\
\text { messages to nodes that have } \\
\text { social ties with them, which } \\
\text { is harmful for message } \\
\text { transmission }\end{array}$ & $\begin{array}{l}\text { Selfishnodes are simulated for } \\
\text { their own benefit to forward } \\
\text { messages for others. }\end{array}$ & $\begin{array}{l}\text { Individual } \\
\text { selfishness }\end{array}$ & $\begin{array}{l}\text { Greedy and real- } \\
\text { time controlled } \\
\text { message replications }\end{array}$ & $\begin{array}{l}\text { Improve the } \\
\text { deanery ratio }\end{array}$ \\
\hline $\begin{array}{l}\text { Data } \\
\text { diffusion [80] }\end{array}$ & $\begin{array}{l}\text { Selfish nodes only forward } \\
\text { messages for nodes that } \\
\text { have social ties with them, } \\
\text { which can reduce the } \\
\text { number of copies }\end{array}$ & $\begin{array}{l}\text { A node has two kinds of contacts: } \\
\text { friends and strangers; messages } \\
\text { are forwarded according to the } \\
\text { type of nodes }\end{array}$ & $\begin{array}{l}\text { Socially } \\
\text { selfish }\end{array}$ & $\begin{array}{l}\text { Real-time controlled } \\
\text { message replication }\end{array}$ & $\begin{array}{l}\text { Reduce the number } \\
\text { of copies }\end{array}$ \\
\hline Friend [81] & $\begin{array}{l}\text { People from the same } \\
\text { community tend to } \\
\text { interact more often } \\
\text { than others from } \\
\text { different communities }\end{array}$ & $\begin{array}{l}\text { Each node builds its friendship } \\
\text { community; messages are } \\
\text { forwarded to destinations or } \\
\text { the node containing destinations } \\
\text { in its community }\end{array}$ & Community & Not mentioned & Reduce traffic created \\
\hline Smitict [82] & $\begin{array}{l}\text { Betweenness can identify } \\
\text { bridge nodes; similarity } \\
\text { can measure the common } \\
\text { characteristics }\end{array}$ & $\begin{array}{l}\text { Message is forwarded to a } \\
\text { structurally more central node }\end{array}$ & $\begin{array}{l}\text { Betweenness } \\
\text { centrality and } \\
\text { similarity }\end{array}$ & Not mentioned & $\begin{array}{l}\text { Delivery performance } \\
\text { close to Epidemic but } \\
\text { with significantly } \\
\text { reduced overhead }\end{array}$ \\
\hline Simbetage & $\begin{array}{l}\text { Betweenness are time- } \\
\text { An varying }\end{array}$ & Extension of SimBet & $\begin{array}{l}\text { Time-varying } \\
\text { betweenness } \\
\text { and similarity }\end{array}$ & Not mentioned & $\begin{array}{l}\text { Delivery performance } \\
\text { can be drastically } \\
\text { improved }\end{array}$ \\
\hline $\begin{array}{l}\text { Simbetage [83] } \\
\text { BubbleRap }\end{array}$ & $\begin{array}{l}\text { Betweenness are time- } \\
\text { An varying } \\
\text { Betweenness can identify } \\
\text { central nodes; community } \\
\text { can reduce traffic }\end{array}$ & $\begin{array}{l}\text { Considering the changes of social } \\
\text { characteristic over time. Nodes } \\
\text { deliver messages up to a more } \\
\text { "popular" node }\end{array}$ & $\begin{array}{l}\text { Time-varying } \\
\text { betweenness } \\
\text { and similarity } \\
\text { Community and } \\
\text { betweenness } \\
\text { centrality }\end{array}$ & $\begin{array}{l}\text { Not mentioned } \\
\text { Not mentioned }\end{array}$ & $\begin{array}{l}\text { Delivery performance } \\
\text { can be drastically } \\
\text { improved } \\
\text { Improve the efficiency } \\
\text { of message transmission }\end{array}$ \\
\hline
\end{tabular}

buffering congestion problem is not well addressed in the design of the protocol, the authors empirically investigated the impact of buffer storage and its size on the successful content delivery ratio.

\subsection{Spray and wait}

Few protocols are socially based routing schemes that are extracted from spray and wait scheme. The Spray and Wait method outperforms all protocols discussed in [28] including the famous Epidemic. The algorithm is based upon two phases, one is spray and the other is wait. In the spray phase, $L$ numbers of message copies are "sprayed" to relays in the social network. At the base of the first phase, the second phase starts with waiting the first phase until it meets the destination in order to deliver the message. Spray and Wait is defined further by the kind of spraying employed. By the source spray, the source sends a message to the first $L$ nodes that are connected. In the binary form of spray, the source has $L / 2$ copies and then distributes the remaining all copies to the first node contacted. The relay thus carries $L / 2$ copies. Such distribution recursively continues until each node has left with one copy. The optimal amount of copies $L^{*}$ can also be derived for a specific delay if required.

\subsection{PROPHET}

The PRoPHET algorithm [29] is based on pairwise contacts for making routing decisions. PRoPHET has the ability to reduce the overhead by calculating a node's delivery probability for the particular destination. If a communicated node $B$ has a higher probability of the delivery for a given message, then carrier $A$ transmits a message to $B$. The delivery probability for a node $A$ depends on encounters of $A$, the age of the encounters, and the also transitive property for mutual encountered nodes of the network. PRoPHET was considered for performing better than Epidemic particularly in the community-based environment and making a comparison with Epidemic for the random mobility use. PRoPHET did not explicitly define a contact graph but it depends on delivery predictability that is a metric used for calculating from the aggregation relisted 
Table 5 Solution, protocol compare, and social characteristics

\begin{tabular}{|c|c|c|c|}
\hline Solution & Unicast or multicast & Protocols for comparison & Social characteristics \\
\hline LABEL [84] & Unicast, multicast & MCP, WAIT, Control & Community \\
\hline BUBBLE RAP [85] & Unicast, multicast & MCP, LABEL, FLOOD,WAIT & Community degree centrality \\
\hline LocalCom [86] & Unicast, multicast & PROPHET, Bubble Rap & $\begin{array}{l}\text { Community tie strength } \\
\text { betweenness centrality }\end{array}$ \\
\hline Friendship-based [87] & Unicast, multicast & PROPHET, SimBet & $\begin{array}{l}\text { Community, friendship, similarity, } \\
\text { tie strength }\end{array}$ \\
\hline Gently [88] & Unicast, multicast & PRPHET & Community \\
\hline DR [89] & Unicast, multicast & SimBet, Epidemic & Community \\
\hline SimBet [90] & Unicast & PROPHET, Epidemic & Betweenness centrality similarity \\
\hline SimBetTs [91] & Unicast & PROPHET, Epidemic & $\begin{array}{l}\text { Betweenness centrality, similarity, } \\
\text { tie strength }\end{array}$ \\
\hline HiBOp [92] & Unicast multicast & PROPHT, Epidemic & $\begin{array}{l}\text { Context information, Social } \\
\text { relationship, similarity }\end{array}$ \\
\hline PeopleRank [93] & Unicast & SimBet & Friendship, similarity \\
\hline Social-based [94] & Multicast & $\begin{array}{l}\text { Epidemic, BubbleRap, } \\
\text { PROPIIET, SimBet }\end{array}$ & Community, centrality \\
\hline Fair Routing [95] & Unicast & Epidemic, PROPHET, SimBet & Community, centrality \\
\hline $\begin{array}{l}\text { Community-aware opportunistic } \\
\text { routing (CAOR) [107] }\end{array}$ & Multicast & PROPHT, Bubble Rep, SimBet & Community, similarity \\
\hline $\begin{array}{l}\text { Zero-knowledge multi-copy } \\
\text { routing }\{108]\end{array}$ & Multicast & Epidemic, Spray and Wait & Community, centrality \\
\hline $\begin{array}{l}\text { Homing spread: community } \\
\text { home-based multi-copy routing } \\
\text { in MSN [108] }\end{array}$ & Unicast multicast & $\begin{array}{l}\text { Epidemic, Home spreading, } \\
\text { Spray and Wait }\end{array}$ & Community, centrality \\
\hline
\end{tabular}

to the wireless graph in the meantime so it suited well within the contact graphs based framework.

\subsection{HiBOp}

History-based opportunistic routing (HiBOp) method [30] utilizes current and past context information's such as the history of node encounters for calculating information delivery probabilities along with their shared attributes. The context information describes the user's environment and it also captures social relationships across nodes. The information is transferred if the communicating node's delivery probability toward the destination is higher than the current node. The source node can replicate message and can also inject the number of copies into the network. HiBOp reduces resources consumption while compared to Epidemic and PRoPHET in a given social-based community. HiBOp message has low loss rate for the limited buffer size of the node. But delay cause is shown to increase with using HiBOp.

\subsection{BUBBLE}

BUBBLE aids the knowledge of node centrality with knowledge of the community structures for making forwarding decisions. Following on the LABEL method, that was the first social-based routing protocol to demonstrate that incorporating a community's affiliation label can improve forwarding messages performance, BUBBLE expands this idea by use of community affiliations label having betweenness centrality measure for forwarding messages [31]. At least two centrality measures have been taken per node based for the node's global popularity throughout the network and local popularity within its communities. The algorithm of bubble calls for the message for transferring to the nodes having high global rankings called centrality measure till the carrier encounters the node having the similar community label like destination node. The message is forwarded then to the node with high local rankings until it is successfully delivered. Such an approach avoids messages from being stuck at a node with a higher global rank, but with no or little affiliations with the destination community.

\subsection{SimBetTS}

SimBetTS is considered as the next iteration of the Daly and Haahr's SimBet methods [32]. The calculations related to similarity and also betweenness centrality by using ego networking can allow for distributed implementations. Whereas the socio-centric networking is pre-defined on global information, egocentric calculations are mostly performed locally by the ego node. The betweenness factor of the SimBetTS measures the bridging 
ability of the nodes, and similarity recognizes nodes socially that are similar to the destination. SimBetTS uses the bridging capability of strong relationships and weak ties that bind clusters together. Tie strength is an indicator for the link availability and is calculated by the frequency of encounter node, the duration is taken by the encounters, and how past contact occurred. The factor of the replication component is included in SimBetTS in order to increase the likelihood of content delivery. While the betweenness measures alone provide the best delivery results. In SimBetTS, combined utility prevents the overload of highly central nodes. Message delivery of the content using SimBetTS is better than the PRoPHET and very close to Epidemic having less overhead.

\subsection{Social-Greedy}

In Social-Greedy forwarding, decision is based on distance and closeness. The closeness centrality is measured between the nodes like the similarity between their social pattern profiles. The profile is composed of seven different fields that are nationality, language, affiliation, graduate school, country, city, and interest. Social-Greedy only transfers a message to the next hop, if it is closer socially to the destination. Similarly, work presented by [66] have shown that Social-Greedy can outperform the LABEL protocol in some cases, but the delivery ratio of BUBBLE and Epidemic is higher than Social-Greedy.

\subsection{Social Cast}

Social Cast is proposed on the basis of common shared interests between the nodes in the networks [65]. Such interests can be used for making forwarding decisions in the Social Cast. The utility function that exists in Social Cast is measured on the base of the co-location of a communicating node with all other nodes having a similar interest. The co-location of communicating node shows that if it has the communication in past with the node that has the same interest at that given time frame. The change in the degree connectivity finds the difference in the encountered node at time frame $t$ with a number at time frame $t$ $-\tau$. Where $\tau$ is the pre- define parameter.

In the work shown by Costa et al., it presents that Social-Cast cost fewer resources than that of Epidemic but Social Cast demands individual nodes to calculate the utility function that can play a vital role to increase the computational complexity of the node level.

\subsection{Status}

Status identifies the fact that the user's node has updated their online status most regularly. For an instant, a user can send messages to all other associated nodes that he is on the way to the supermarket. Another user may update that they are in the shopping mall. On the basis of the available online status of the entire user, a message within the Status routing protocol can be forwarded to the popular position in the city, which is termed as points of interest (PoI). Such PoI is considered to be more likely to become a destination node or it can be a node that can pass the message to its destination. Whenever the message reaches PoI, the carrier is used to find if the destination is there. Otherwise, the message is transmitted to nodes that are going to other PoIs. This shows that the message travels through different PoIs before approaching its destination. A message in STATUS is also transferred to an encountered node if there is the same neighborhood as the like destination node such information can be obtained from the online profile of the communicating nodes. Status utilizes the online profile and status of a node for forwarding messages.

Status has got low computational complexity and also the overhead ratio at the node level; this messages are only transferred with nodes that are reaching to the PoI, hence no such mathematical computations are done. Status has a disadvantage for getting a slow start problem, which can cause low content delivery ratio whenever a message is generated due to slow content dissemination. Improved Status is proposed in order to solve the problem of slow start with Status. Improved Status aided Status with the Epidemic routing protocol. An Epidemic can be used at the beginning for Improved Status for initializing forward message more frequently. After a particular time, interval, Improved Status switches again to the Status routing protocol just to take benefit of its low overhead ratio. Label Status is proposed in order to further improve the content delivery ratio by keeping the overhead ratio reasonable. As LABEL has a very low overhead ratio, so it was combined with Improved Status. Table 6 presents the CDN proposal for MSN.

\subsection{Community-based routing}

There exist two famous social community-based routing schemes. One is a distributed optimal Community-Aware Opportunistic Routing (CAOR) algorithm [107]. CAOR propose a home-aware community model, whereby the algorithm turns an MSN into a network that only includes community homes. It shows that in the network of community homes, CAOR computes the minimum expected delivery delays of nodes through a reverse Dijkstra algorithm and achieve the optimal opportunistic routing performance.

The other routing scheme is home-based zero-knowledge multi-copy routing algorithm, homing spread (HS), for homogeneous MSNs, in which all mobile nodes share all community homes [109]. HS is a distributed and localized algorithm. It mainly lets community homes spread messages with a higher priority. HS can spread a given number of message copies in an optimal way when the 
Table 6 CDN challenges in MSN

\begin{tabular}{|c|c|c|}
\hline Method & Challenges & Contributions \\
\hline [96] & $\begin{array}{l}\text { Startup } \\
\text { latency (QoS) }\end{array}$ & $\begin{array}{l}\text { Proposed for the purpose of downloading the initial packets of a content item that is } \\
\text { from the closed CDN nodes geographically }\end{array}$ \\
\hline [97] & $\begin{array}{l}\text { Startup } \\
\text { latency (QoS) }\end{array}$ & $\begin{array}{l}\text { Proposed an efficient technique for the buffer management which distribute the client's } \\
\text { buffer among the ON region }\end{array}$ \\
\hline [98] & $\begin{array}{l}\text { Startup } \\
\text { latency (QoS) }\end{array}$ & $\begin{array}{l}\text { Proposed for the division of the playback of the buffer into the CDN region, an emergency } \\
\text { region along with a peer region. The peer region is transformed to an emergency region } \\
\text { in the case of the user failure to download the required content from neighboring peers } \\
\text { before the playback deadline }\end{array}$ \\
\hline [99] & $\begin{array}{l}\text { Startup } \\
\text { latency (QoS) }\end{array}$ & $\begin{array}{l}\text { Proposed for P2P resources and scheduling algorithm for the purpose of achieving fewer } \\
\text { startup delays }\end{array}$ \\
\hline [100] & $\begin{array}{l}\text { Startup } \\
\text { latency (QoS) }\end{array}$ & $\begin{array}{l}\text { Proposed the chunk pre-fetching based algorithm build on social relationships along with } \\
\text { the physical position of peers in online social networks (OSNs) }\end{array}$ \\
\hline [101] & $\begin{array}{l}\text { Playback } \\
\text { latency (QoS) }\end{array}$ & $\begin{array}{l}\text { Proposed an algorithm called location-based peer selection by the induction of a CAN . } \\
\text { method that clusters peers that is based on the delays and the channel streaming they } \\
\text { are watching }\end{array}$ \\
\hline [102] & Inaccessibility & $\begin{array}{l}\text { Proposed an architecture known as CDN centralized hybrid architecture that is based on } \\
\text { BitTorrent to solve the problems of firewalls }\end{array}$ \\
\hline [103] & Authentication & $\begin{array}{l}\text { A proposed a scheme for peer authorization with the help of a network coding scheme } \\
\text { for the purpose of preventing illegal distribution of the content within the network }\end{array}$ \\
\hline [104] & Copyright & $\begin{array}{l}\text { Proposed architecture called centralized PA-CDN, such architecture used tracker server } \\
\text { to authorize the users }\end{array}$ \\
\hline
\end{tabular}

inter-meeting time between any two nodes and between a node and a community home follows independent and identical exponential distributions. By using homes to spread messages faster, HS achieves a better performance than existing zero-knowledge MSN routing algorithms, including Epidemic and Spray and Wait [108].

\section{$5 \mathrm{MSN}$ routing protocols performance}

Existing MSN routing is supposed to achieve a high delivery ratio along with low memory cost. A low delivery ratio can result in many packets that are not arriving at their destination, whereas high memory requirements can lead to excessive consumptions of node resources. The designing of new socially based protocols aim is to maximize the content delivery ratio and minimize the memory requirement. Moreover, average latency, low overhead ratio, hop count, and computational complexity are desired at the node level.

Delay tolerant network is created due to the partition of the wireless network. Connectivity for communication exists within the cluster, but protocols depend on mobile nodes to route messages throughout the communities. Protocols utilizing flooding for communication in the network carefully identifying bridge nodes that are responsible for carrying and forward data. Improvements to standard schemes of routing in social networks like Epidemic, Spray and Wait, and PRoPHET have shown performance enhancements in terms of reduced communication overall costs and comparable content delivery ratio. Predicting and also exploiting pairwise contact have led to the extension of social networking theory towards wireless network shown in Tables 7 and 8 .

\section{Content distribution in MSN}

The content distribution throughout the MSN is a core issue because of its sparse connectivity consisting of limited node resources on the mobility. To ensure smooth content distribution in the MSN, several underlying methods are used to address the most suitable forwarding nodes or links to increase the content delivery ratio and network efficiency. The vital factors that can be used to encounter in the content distribution of among the nodes of MSN are the utilization of the bandwidth, time and mobility, sharing location information along with the time of the encounters, updated content, and the duplication of messages contents that are available to the mobile user shown in Fig. 3.

For the sake of content dissemination, nodes of MSN can be used for opportunistic contacts due to its diverse architecture and system design. Similarly, the users of the MSN can receive updated content with the exchange of message in a way of delay tolerant to the network without having connections to the fixed infrastructure. In [33], all the users are connected to a centralized server for the authentication of themselves, and users are required to communicate P2P fashion shown in Table 7. An attempt was made to overcome message duplication for reducing the overhead across the whole network. This simple method was successfully implemented for the message duplication and reduction of about $71.8 \%$ as the best and $14.8 \%$ in the worst case. Another work which was done in [34] is the discovery to 
Table 7 Summarized various techniques and performances

\begin{tabular}{|c|c|c|c|c|}
\hline Techniques & Path length & Out degree (max) & $\begin{array}{l}\text { Node avg control } \\
\text { overhead }\end{array}$ & $\begin{array}{l}\text { No of state entries } \\
\text { per node }\end{array}$ \\
\hline ALMA & Max: unbounded & User-defined & $\mathrm{O}(\max \mathrm{deg})$ & $\mathrm{O}(\max \mathrm{deg})$ \\
\hline ALMI & Max: unbounded & User-defined & $\mathrm{O}(\mathrm{N})$ & $\mathrm{O}(\mathrm{N})$ \\
\hline ALM-CAN & $\begin{array}{l}\operatorname{Max}: O\left(d N^{1 / d}\right) \\
\text { Avg }: d / 4 N^{1 / d a}\end{array}$ & Constant of $2 \mathrm{~d}$ & Constant of $2 d$ & Constant of $2 d$ \\
\hline ALM-DT & Avg $: \sqrt{N} / 4$ & $\begin{array}{l}\text { Worst: } O(N-1)^{b} \\
\text { Avg: approx. } 6\end{array}$ & Constant of 6 & Constant of 6 \\
\hline Bayeux & Max : $O\left(\log _{b} N\right) \hat{c}$ & $O\left(\log _{b} N\right)$ & $O\left(\log _{b} N\right)$ & $O\left(b \log _{b} N\right)$ \\
\hline BTP & Max: unbounded & Unconstrained & $\mathrm{O}(\mathrm{N})$ & $\mathrm{O}(\mathrm{N})$ \\
\hline HM & Max: unbounded & User-defined & O (max. Deg.) & O (max. Deg.) \\
\hline Kudos & Max: unbounded & $O(\sqrt{ } N)$ & $O(\sqrt{ } N)$ & $O(\sqrt{ } N)$ \\
\hline Narada & Max: unbounded & $\begin{array}{l}\text { User-defined to reflect } \\
\text { bandwidth of user's } \\
\text { outgoing link }\end{array}$ & $\mathrm{O}(\mathrm{N})$ & $\mathrm{O}(\mathrm{N})$ \\
\hline NICE & Max: $O(\log N)$ & Between $k$ and $3 k^{d}$ & $\begin{array}{l}\text { Constant of } O(k) \\
\text { Max: } O(k \log N)\end{array}$ & $\begin{array}{l}\text { Constant of } \mathrm{O}(\mathrm{k}), \mathrm{O}(\mathrm{k} \log \mathrm{N}) \text { only } \\
\text { for the highest hierarchical layer }\end{array}$ \\
\hline OMNI & Max: $O(\log N)$ & $\begin{array}{l}\text { MSN defined to reflect } \\
\text { bandwidth of MSN's } \\
\text { outgoing link }\end{array}$ & $O(\max$. deg. $+\log N)$ & $\mathrm{O}(\max$. deg. $+\log N)$ \\
\hline Overcast & Max: unbounded & Unconstrained & $\mathrm{O}(\mathrm{N})$ & $\mathrm{O}(\mathrm{N})$ \\
\hline Scattercast & Max: unbounded & $\begin{array}{l}\text { User defined to reflect } \\
\text { bandwidth of user } \\
\text { outgoing link }\end{array}$ & O (max. deg.) & O (max. deg.) \\
\hline SCRIBE & Avg: $O\left(\log _{2}^{b} N\right)$ & $O\left(\log _{2}^{b} N\right)$ & $O\left(\log _{2}^{b} N\right)$ & $O\left(\left(2^{b}-1\right) \log _{2}^{b} N\right)$ \\
\hline TBCP & Max: unbounded & User defined & O (max. deg.) & O (max. deg.) \\
\hline Yoid & Max: unbounded & User defined & O (max. deg.) & $\mathrm{O}$ (max. deg.) \\
\hline
\end{tabular}

provide a useful and novel control method where information is successfully delivered to all mobile stations by the utility of the cache function of the mobile network.

In the work done in [35], mobile social computation middleware was proposed that provide a platform for capturing, sharing, and managing the social communities. Another middleware framework known as Broad Speakin [36] is proposed for the vehicular social networks to that provide virtually the chat social community for those users driving on the road. Such overlay middleware is using the centralized server for managing the profile and related activities of the mobile users. The benefits of using centralized architecture add the simplicity of the service implementation and also improve the efficiency of centralized control. The authors of research work [37] presented the scheme of middleware-related software for dynamic

Table 8 Social pattern techniques

\begin{tabular}{|c|c|c|}
\hline Publication & Proposed algorithm & Social patterns \\
\hline [87] & $\begin{array}{l}\text { Uses probabilistic routing scheme to forward a message } \\
\text { to the node or group which is currently in contact with } \\
\text { the source of the message }\end{array}$ & $\begin{array}{l}\text { Using frequency and time duration of contact to } \\
\text { find contact pattern }\end{array}$ \\
\hline$[88]$ & $\begin{array}{l}\text { Uses weak ties for content distribution into otherwise } \\
\text { disjoint communities }\end{array}$ & Mobile user contacts to find the relational strength \\
\hline [37] & $\begin{array}{l}\text { Uses flooding concepts to disseminate the data in the } \\
\text { detected communication }\end{array}$ & $\begin{array}{l}\text { Social centrality measures are used to identify the } \\
\text { nodes with a higher number of social links }\end{array}$ \\
\hline$[90]$ & $\begin{array}{l}\text { Uses graph and spanning tree concept to reduce the } \\
\text { message duplication during content distribution }\end{array}$ & $\begin{array}{l}\text { By exploiting mobility predictability property of the } \\
\text { users, the node which has the earliest probability } \\
\text { of encountering the destination is only allowed to } \\
\text { retain the message }\end{array}$ \\
\hline$[91]$ & $\begin{array}{l}\text { A forwarding algorithm is proposed for selfish nodes } \\
\text { where certain information such as message content } \\
\text { and sender information are force fully }\end{array}$ & $\begin{array}{l}\text { Exploits the selfish behaviour such that a selfish } \\
\text { node in fear of losing information accepts to relay } \\
\text { the information }\end{array}$ \\
\hline
\end{tabular}




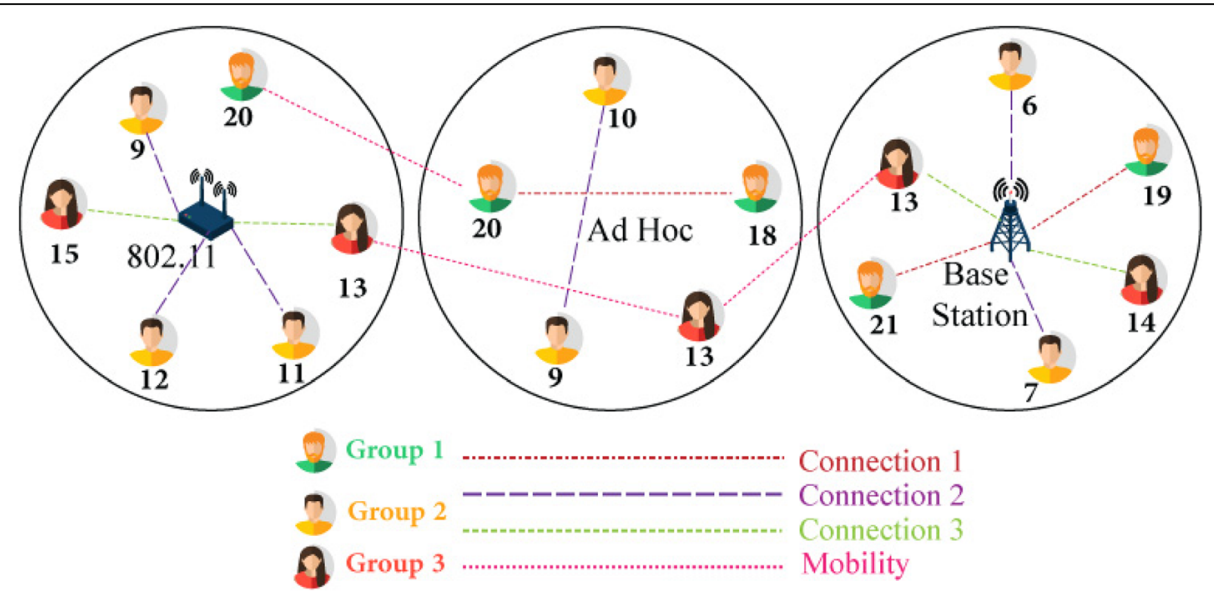

Fig. 3 Content distribution in MSN

creation group and management for the social network in mobile communication. Such social networking middleware was implemented that is based on peer to peer networks that works as a personal area network called PAN in order to provide a communication system environment for mobile nodes. The mobile users are free to communicate directly without having centralized server. Similarly,

Mobi Clique approach for middleware [38] is developed for MSN utility. Using this middleware, mobile users can form ad hoc network using store carry and forward method. Mobi Clique is helpful for mobile users to extend and maintain their virtual social network, which is beyond their physical environment via opportunistic encounters. However, such opportunistic contacts introduce the issues related to community detection, content distribution, routing, and delivery delay. In [39, 63], an architecture of hybrid mobile social networking is introduced for a mobile transient network by utilizing multimedia devices. Multimedia devices encounter with the content provider through cellular networks and in parallel they can also form an ad hoc network by utilizing Bluetooth and Wi-Fi radio interfaces. Such hybrid architecture consists of an intelligent agent, which exploit the social relationships among users while sharing the similar interest to cooperatively share and retrieve remote contents. Cellular network can be useful for the better performance of content delivery and ad hoc network. A recent effort was done to quantify the centrality in the domain of sensor network in [40] as the $\mu$ power community index. Such metric supposes the degree of a node along with the degree of the nodes as $\mu$-hop neighbors.

In [41], hybrid middleware framework was proposed which is based on Jini Surrogate Architecture wrote as JS. In [42], a similar research work was carried out to support the progress of social network services and applications in the MSN. The proposed middleware has the capacity to enable a Smartphone device by mobile service provisioning for both remote and local users in the MSN. In [42], the JSA middleware is upgraded by the discovery mechanism by using surrogates to surrogate communication protocol so that it can provide facilities for the exchange the information between service providers and service requesters. In addition, a cache function mechanism was added to $\mathrm{SH}$ to increase scalability and availability.

The social pattern of users influences both the interest and their willingness called selfish behavior for sharing the content of among the nodes [43, 64]. In [44], social pattern of mobile node such as duration of time and frequency of the contact called social tie strength is used to calculate the contact pattern of the communicating nodes to build the required social community for opportunistic contacts. In [45], the concept of flooding is used for disseminating the content in the detected social community. But message flooding cause traffic load on the network which can cost bandwidth usage, memory consumption, and energy as well. In [110], a time-ordered aggregation method was proposed and combines with the proposed scheme of centrality metric cumulative neighboring relationship (CNR) to calculate the most import nodes in a certain time interval. Finally, extensive trace-driven simulations are performed to measure the performance of the proposed time-ordered aggregation model-based centrality metric and time-ordered cumulative neighboring relationship (TCNR). In this method, it is proved that the exponential time-ordered aggregation method can measure TCNR centrality in a certain time interval more accurately than other aggregation methods.

In [46], simple message duplication for the reduction algorithm was presented that is using mobility predictability properties of the users in the MSNs. So such proposed algorithm utilized larger memory as it is using graphs for storing the information of nodes and also the 
vertices and edges. In [47], the performance of the hierarchical super node under different configurations is analyzed and investigated. The configuration parameters of this scheme are super node neighbor numbers, super node redundancy, and also request TTL. In [48], another factor of super node selection streaming application and file sharing is discussed. The authors have given theoretical techniques for selection of a super node scheme.

A clustering scheme [104] named as the credit-based clustering $(\mathrm{CBC})$ scheme for point of interests' (POIs') geo data sharing in vehicular social network (VSN). In the proposed $\mathrm{CBC}$ scheme, a number of vehicles that belong to the same VSN can form a cluster to download POIs' geo data when they are approaching to a new set of POIs. One vehicle is selected as the cluster head to download POIs' geo data using its cellular network and shares the downloaded POIs' geo data to its cluster members using IEEE 802.11p network. Their work in [104] showed that the proposed scheme can achieve the goal of fairness, the higher successful ratio of the complete sharing of downloaded POIs' geo data, and the better receiving efficiency. Recently, for satisfying users' various mobile Internet service requests for data exchange anytime and anywhere even in their moving vehicles, the generated mobile data traffic has been rapidly increasing and has become a serious burden on current cellular networks [105].

Nazir et al. have suggested that mobility pattern can be useful in predicting keeping the record duration of encounters. Such kind of information can help for the improvement of the content delivery ratio by reducing the delivery delays. Similarly, Costa et al. [49] proposed efficient message routing for publishing network using the co-location and also the movement patterns of the users in this scheme is called SocialCast. The co-location metric is added to the mobility pattern for predicting the availability of mobile nodes so that appropriate forwarding node can be selected for content dissemination. In [50], another scheme is proposed to help unconnected mobile users toward connecting mobile users in the MSN. Since connected nodes are connected to the main server via the base station, the unconnected nodes can use these connected users as the relays for their connectivity. In [51], an optimal method for the content update is presented to distribute the updated content from the content provider to the mobile users.

\subsection{Social pattern}

The presence of opportunistic contacts entirely relies on the probability of encounters to all other nodes. Social patterns are measured in the shape of the user's social behavior, connectivity pattern, interests, and contact duration. The social pattern affects both interest and their willingness to share the content. The social pattern for instant frequency and duration of time for contact can be used to know the contact pattern of all nodes to create a required social mobile group of opportunistic contacts. The contact pattern information of the social mobile nodes is useful for increasing the message successful delivery ratio and decreases the average delay as shown in Tables 8 and 9.

The knowledge related to the social pattern is considered as an added advantage of the related opportunistic contacts that can be measured as the capacity that is available for the freshness of the content. Because of the intermittent connectivity and also the uncertainty of future communications, most of the forwarding protocols replicate the message in order to increase the probability related to message delivery. Selfish behavior is one of the common issues, where mobile users want more and less in return. The selfish nodes in MSN are simply dropping every message except those required by them. If the selfish node is offered by incentives, it can be motivated for carrying and forwarding the message.

Cabbiniss et al. [52] used probabilistic routing scheme to forward the message to a node or group currently in the contact of the source message. In this method, they utilize the frequency and time duration of the contact to find contact pattern. It is a simple scheme to ensure message delivery with less delay. Loannidis et al. [53] used week ties for content distribution in disjoint communities. Week ties help in speeding up the content distribution and also expand the MSN. Yone ke et al. [54] utilize flooding concept in disseminating the data in the detected community. The message flooding increases the amount probability of delivering a message. Kawarabayashi [55] used graphs and spanning tree to reduce the message duplication during the content distribution.

Table 9 Various methods compare centralized/distribution approaches

\begin{tabular}{lll}
\hline Methods & Characteristics & Centralized/distributed \\
\hline$[84]$ & Movement added & Distributed \\
{$[85]$} & Movement assisted & Distributed \\
{$[86]$} & Movement assisted & Distributed \\
{$[87]$} & Potential fields & Distributed \\
{$[88]$} & Potential fields & Distributed \\
{$[89]$} & Potential fields & Distributed \\
{$[90]$} & Virtual force & Centralized \\
{$[91]$} & Virtual force & Centralized \\
{$[92]$} & Grid quorum & Distributed \\
{$[93]$} & Grid quorum & Distributed \\
{$[94]$} & Flooding and Zone & Distributed \\
{$[95]$} & Mesh & Distributed \\
{$[96]$} & Mesh & Distributed \\
\hline
\end{tabular}


It is the simple technique but cost larger memory to store the information of edges and graphs. Mei et al. [56] proposed a forwarding algorithm for the selfish node where certain information such as message content and sender information is hidden. They exploit the social behavior such as social node in the fear of losing information.

\subsection{Mobility pattern}

Mobility is considered to be one of the factors in the MSN because mobile systems are carried by the people. Social group is created in case of encounter patterns that are repeatable consistent. By keeping control of the mobility pattern of the users that are based on selection criteria so that mobile nodes of social community can be directed toward the specific destination as shown in Table 10.

Nazir et al. [2] present time duration and social encounter for predicting the mobility pattern in MSN for efficient content distribution; a social group can be formed and deducing the consistent social encounter. Costa et al. [53] provide efficient content routing called social cast is presented for publishing network using collocation and movement pattern of the users for content distribution. Chelly and Molouc [57] introduces an algorithm for directing and unconnected user toward connected user using the location-based MSN service. They targeted converge for a node that is needed to build a connection tree. Chaintreau et al. [58] used underlying online social services for exploiting mobility behavior to enhance the performance of the MSN. They prove that opportunistic contact between the nodes can be used to construct social relation and mobility model.

\subsection{Opportunistic approaches}

In the opportunistic contacts, the nodes itself are able to construct social communities. MSNs community detection can play a vital role in the distribution of content. Several social analysis metrics such as social tie strength, closeness, and also the mobility pattern. Some optimization approaches that are employing optimizing utility functions are used to distribute the content to the entire mobile user in the MSN in shown Table 11.

Most of the schemes for the content distribution rely on utility-based selection criteria for the optimization of the data dissemination. Generally, the utility is related to some of the social metrics for evaluations of the effectiveness of the algorithms that are proposed. The content inserted from the content providers goes within the network by the encounters of the mobile nodes. In such case, the old existing contents can be replaced by the new contents having opportunistic contacts. The important utility function knows as social welfare is given that act as a decreasing function the content age. The objective is finding the optimal bandwidth allocation that can help to maximize the utility $[102,103]$.

Some of the updates of the content are provided by the content provider, but optimization for the content distribution is an issue. In practical, network operator and content providers are two different systems that take part in the distribution of the content in the MSNs. The main objectives of the content providers and network operators are not similar. The content providers minimize the cost for bandwidth utilization and also minimize the delay. While the network provider's tries to maximize the revenue generated from selling wireless services.

The work done in [59] proposed utility-based schemes for opportunistic networks that can exploit the context-related information about the social behavior of users to look for the appropriate forwarding node. The content dissemination depends on the tradeoff among the utility of the content object and the also the cost consumption on resources that can be calculated locally. Any communicating node can select the content for transferring based on such measures in order to maximize the utility under limited resources. Similarly, the work done in [11] provides social-oriented strategies to optimize the content availability by the use of a system known as B content place. It follows the concept

Table 10 Mobility pattern

\begin{tabular}{|c|c|c|}
\hline Publication & Proposed algorithm & Mobility patterns \\
\hline [92] & $\begin{array}{l}\text { Uses time and contact duration of a social encounters for } \\
\text { predicting the mobility pattern in the MSN for efficient } \\
\text { content distribution }\end{array}$ & $\begin{array}{l}\text { Mobility pattern can be predicted for a given period } \\
\text { for the time depending upon time and contact duration }\end{array}$ \\
\hline [93] & $\begin{array}{l}\text { An efficient message routing (called, "SocialCast") is } \\
\text { presented for publish/subscribe network for content } \\
\text { distribution using colocation and movement patterns } \\
\text { of the users }\end{array}$ & $\begin{array}{l}\text { The colocation metric together with mobility pattern is } \\
\text { used to predict the availability of forwarding nodes }\end{array}$ \\
\hline [94] & $\begin{array}{l}\text { Introduction an algorithm for directing an unconnected } \\
\text { user using location-based service in the MSN }\end{array}$ & $\begin{array}{l}\text { Attraction force function, which defines the attraction } \\
\text { between nodes, is used }\end{array}$ \\
\hline$[95]$ & $\begin{array}{l}\text { Uses underlying online social network services for exploding } \\
\text { mobility behaviour to enhance the performance of the MSN }\end{array}$ & Uses link traces from an online social network \\
\hline
\end{tabular}


Table 11 Opportunistic approaches

\begin{tabular}{|c|c|c|}
\hline Publication & Proposed algorithm & Optimization criterion \\
\hline [96] & $\begin{array}{l}\text { Global utility function (social welfare) is defined as a } \\
\text { decreasing function of content age, and maximizing } \\
\text { this utility provides optimal bandwidth solution for } \\
\text { scalable content distribution in the MSN }\end{array}$ & $\begin{array}{l}\text { Finds the optimal bandwidth maximizes the utility function } \\
\text { (social welfare) }\end{array}$ \\
\hline [97] & $\begin{array}{l}\text { Content distribution policy of a content provider is } \\
\text { optimized for maximizing the fresh content in the MSN }\end{array}$ & Maximizes the number of mobile users having fresh data \\
\hline [98] & $\begin{array}{l}\text { Uses a coalitional game model to investigate the decision } \\
\text { making of the content providers and network operators } \\
\text { for optimizing the content distribution }\end{array}$ & $\begin{array}{l}\text { Minimizes the cost of wireless connection for the content } \\
\text { provider and maximizing the revenue for network operators }\end{array}$ \\
\hline [99] & $\begin{array}{l}\text { A general utility-based framework is proposed for opportunistic } \\
\text { networking which exploits the context information about } \\
\text { the user's social behavior to find the appropriate forwarding nodes }\end{array}$ & $\begin{array}{l}\text { A utility is a function of the data object (content) and the } \\
\text { cost of resource consumption }\end{array}$ \\
\hline [100] & $\begin{array}{l}\text { A social-oriented policy for optimizing content availability using } \\
\text { a system called "Content-Place" is proposed }\end{array}$ & $\begin{array}{l}\text { Optimizes the content availability by using utility of data } \\
\text { object which is computed based on the needs of the social } \\
\text { communities in which the node resides }\end{array}$ \\
\hline [101] & $\begin{array}{l}\text { A utility-based routing scheme (i.e., SimBet) is introduced to } \\
\text { find the best forwarding node in an opportunistic network }\end{array}$ & $\begin{array}{l}\text { SimBet utility is calculated based on social network metrics } \\
\text { such as betweenness and social similarity which is used to } \\
\text { select the node that provides maximum utility for carrying } \\
\text { the message }\end{array}$ \\
\hline
\end{tabular}

based on social behavior which is useful to create a group for mobile users depending on their interests and also social ties. Normally, every user advertises his interested content objects that they want upon for making contact with every other node. Utility value is defined for each content object that is computed based which is the needs of the social group. The content objects are made available in the network if only its utility value is very high; as a result, the processes help to optimize the content availability.

Loannidis et al. [60] proposed globally utility faction (social welfare) is defining as the decreasing fraction of the content and thus maximizing optimal the bandwidth solution for content distribution. This scheme addresses the optimality and scalability of the dynamic content distribution of MSN. Niyato et al. [61] content distribution policy of the content providers is optimized for maximizing the fresh content distribution. They highlighted the content distribution form the content provider's perspectives. Daly and haahr et al. [62] proposed a utility-based routing scheme (SimBet) to find the best forwarding path. Social metric was used for the content distributions in MSN.

\section{Discussions}

The MSN can be counted as a system which supports a variety of content delivery services by the involvement of the social relationship among mobile users. The unique characteristics of social relationship with MSN give rise to different protocol design issues. Content delivery networks (CDNs) improves the network performance of MSN and offer fast and reliable applications and services by distributing content through some agents located close to the social community. MSN is a special kind of delay tolerant network (DTN) composed of mobile nodes that move around and share information with each other through their carried short-distance wireless communication devices. A main characteristic of MSNs is that mobile nodes in the networks generally visit some locations (namely, community homes) frequently, while visiting other locations less frequently. To support different data exchange, sharing, and delivery scenarios, different MSN architectures can be developed. The fundamental working principle of architectural and protocol design to improve the overall performance of the MSN in term of End-to-End content delivering ratio, decreasing delay and the removal of the congestion before it happens. Efficient content delivery in MSN benefits includes reduced origin server load, reduced latency for end users, and increased throughput.

In MSNs, mobile users move around and use their carried wireless devices to share information through online social networking services, such as QQ, Wexin, Facebook, Twitter, etc. Recently, the model of the short-distance communication has also been applied by encountered mobile users in MSNs, such as large-size files multimedia content, at a low network cost. Since MSNs can be seen as one kind of DTN. As the links among mobile users and the network topology are changeable, hence MSN can be regarded as a special type of DTN, which makes content delivery a challenging problem in MSN. In the context of routing, comparing with traditional path-building-based routing approaches such as AODV, OLSR, and DSR, Store-carry-and-forward strategy-based routing is more efficient 
for content delivery. In these routing schemes, mobile users can act as mobile relays and store and carry data till the next hop is available. These proposed strategies may play the role to overcome the intermittent links of MSN. However, such opportunistic encounter-based methods still have some level low content delivery efficiency. More new methods and schemes are required from the research community to improve the overall performance of MSN.

\section{Acknowledgments}

This work is supported by the Start-up research grant project of Jiangsu University of Science and technology and School of Electronic and Information of JUST.

\section{Funding}

This work is supported by the Start-up research grant project of Jiangsu University of Science and Technology and School of Electronic and Information of JUST.

\section{Availability of data and materials}

No data were used to conduct this study.

\section{Authors' contributions}

RA and YS designed and prepared the basic structure of the Survey. ZZ focused on figures and the maintained the tables in manuscript. IM and ZAK searched out the new schemes. RA and SR wrote the paper. RA, ZZ, and SA analyzed and compared with an existing survey of the MSN. All of the authors participated, and they read and approved the final manuscript.

\section{Competing interests}

The authors declare that they have no competing interests.

\section{Publisher's Note}

Springer Nature remains neutral with regard to jurisdictional claims in published maps and institutional affiliations.

\begin{abstract}
Author details
'School of Electronics and Information, Jiangsu University of Science and Technology, Zhenjiang, People's Republic of China. ${ }^{2}$ Department of Information Engineering, Jiangsu Union technical institute, Zhenjiang, Jiangsu, People's Republic of China. ${ }^{3}$ Department of Electrical Engineering, Comsats University of Information Technology, Attock Campus, Islamabad, Pakistan. ${ }^{4}$ Bahria University Karachi Campus (bukc), Karachi, Sindh, Pakistan.
\end{abstract}

Received: 11 November 2018 Accepted: 25 April 2019

Published online: 23 May 2019

\section{References}

1. S. Wasserman, F. Faust, Social network analysis: methods and applications (Cambridge Univ. Press, Cambridge, 1994)

2. F. Nazir, J. Ma, A. Seneviratne, in Proc. Int. Conf. Comput. Sci. Eng.. Time critical content delivery using predictable patterns in mobile social networks, vol 4 (2009), pp. 1066-1073

3. Osman Khalid, Muhammad Usman Shahid Khan, Samee U. Khan, Albert Y. Zomaya, "OmniSuggest: A ubiquitous cloud-based context-aware recommendation system for Mobile social networks" IEEE Transactions on Services Computing, Vol. 7. July-Sept. 2014, pp. 401-414. https://doi.org/10. 1109/TSC.2013.53

4. C. Huang et al., in Proc. NOSSDAV. Understanding hybrid CDNP2P: why limelight needs its own red swoosh (2008), pp. 75-80

5. T. Leighton, Improving performance on the internet. Commun. ACM 52(2), 4451 (2009)

6. D. Chatzopoulos, M. Ahmadi, S. Kosta, P. Hui, in IEEE Communications Magazine, vol. 54, no. 7. OPENRP: A reputation middleware for opportunistic crowd computing (2016), pp. 115-121. https://doi.org/10.1109/MCOM.2016. 7509388

7. S.U. Khan, Mosaic-net: A game theoretical method for selection and allocation of replicas in ad hoc networks. J. Supercomput. 55(3), 321-366 (2011)
8. G. Ding, B. Bhargava, in IEEE Annual Conference on Pervasive Computing and Communications Workshops. Peer-to-peer file-sharing over mobile ad hoc networks (2004. Proceedings of the Second), pp. 104-108

9. N.D. Ziv, B. Mulloth, in Proc. Int. Conf. Mobile Business. An exploration on mobile social networking: dodgeball as a case in point (2006), p. 21

10. P. Dhakan, R. Menezes, in Proc. ACM Southeast Regional Conf.. The role of social structures in mobile ad-hoc networks (2005), pp. 59-64

11. C. Boldrini, M. Conti, A. Passarella, in Proc. ACM Int. Symp. Model. Anal. Simul. Wireless Mobile Syst.. Contentplace: social-aware data dissemination in opportunistic networks (2008), pp. 203-210

12. L. Pelusi, A. Passarella, M. Conti, Opportunistic networking: data forwarding in disconnected mobile ad hoc networks. IEEE Commun. Mag. 44(11), 134141 (2006)

13. O. Khalid, S. U. Khan, J. Kolodziej, L. Zhang, J. Li, K. Hayat, S. A. Madani, L. Wang, and D. Chen, "A Checkpoint Based message forwarding approach for opportunistic communication," in 26th European Conference on Modeling and Simulation (ECMS), Koblenz, Germany, May 2012, pp. 512-518

14. J. Kolodziej, S.U. Khan, L. Wang, N. Min-Allah, S.A. Madani, N. Ghani, H. Li, in 9th IEEE International Conference on Frontiers of Information Technology (FIT), Islamabad, Pakistan. An application of Markov jump process model for activity-based indoor mobility prediction in wireless networks (December 2011), pp. 51-56

15. K. Fall, in Proc. ACM Conf. Appl. Technol. Architect. Protocols Comput. Commun.. BA delay-tolerant network architecture for challenged Internets (2003), pp. 27-34

16. Z. Zhang, Routing in intermittently connected mobile ad hoc networks and delay tolerant networks: overview and challenges. IEEE Commun. Surv. Tut. 8(1), 24-37 (2006)

17. M. Conti, J. Crowcroft, S. Giordano, P. Hui, H.A. Nguyen, A. Passarella, Middleware for network eccentric and mobile applications (Springer-Verlag, Berlin, 2009)

18. W.-J. Hsu, A. Helmy, in Proc. IEEE Int. Workshop Wireless Netw. Meas.. On nodal encounter patterns in wireless LAN traces (2006)

19. B. R. Karki, A. Hamalainen, and J. Porras, Social networking on mobile environment, in Proc. ACM/IFIP/ H

20. Zhong, L. Bi, Z. Feng, N. Li, in Proc. Int. Conf. Inf. Manage. Innovat. Manage. Ind. Eng.. Research on the design method of mobile social network services, vol 2 (2008), pp. 458-446

21. iPhone Facebook Applications. Available: https://www.facebook.com/ games/fbiphone

22. Google Latitude. Available: https://en.wikipedia.org/wiki/Google_Latitude

23. J. Kemp, F. Reynolds, in Proc. W3C Workshop Future of Social Netw.. Mobile social networking: two great tastes (2009)

24. Eyevibe. Available: https://bestmobileappawards.com/app-submission/ eyevibe

25. M. Conti, M. Kumar, Opportunities in opportunistic computing. Computer $43(1), 42-50(2010)$

26. M. Bigrigget al., "Routing through an integrated communication and social network," Proc. IEEE MILCOM, Boston, MA, 2009, pp. 1-7

27. A. Vahdat, D. Becker, in Duke Univ., Tech. Rep. CS-2000-06. Epidemic routing for partially-connected ad hoc networks (2000)

28. T. Spyropoulos, K. Psounis, C.S. Raghavendra, Efficient routing in intermittently connected Mobile networks: the multiple-copy case. IEEE/ ACM Trans. Net. 16, 77-90 (2008)

29. P. Dini, P. Lorenz, J.N. de Souza, Service Assurance with Partial and Intermittent Resources, Ser. LNCS, Ed, First International Workshop, SAPIR 2004, August 1-6, 2004. Proceedings, Vol 3126 (Springer, Fortaleza, Brazil, 2004), pp. 239-54.97

30. R Akhtar, S Leng, F Wu, I Memon "Improvement of content delivery in mobile social networks" 2013 International Conference on Computational Problem-Solving (ICCP), 139-143

31. P. Hui, J. Crowcroft, E. Yoneki, BUBBLE rap: social-based forwarding in delay tolerant networks. IEEE Trans. Mob. Comput. 10(11), 15761589 (2011)

32. E. Daly, M. Haahr, Social network analysis for information flow in disconnected delay-tolerant MANETs. IEEE Trans. Mob. Comput. 8(5), 606-621 (2009)

33. W. On, E.-P. Lim, J. Jiang, F.C.T. Chua, V.-A. Nguyen, L.-N. Teow, in IEEE International Conference on Social Computing. Messaging behavior modeling in mobile social networks (2010)

34. T. Koshimizu, Yokosuka-shi, Koji Sasada and Kamakura-Shi US Patent 2002/ 0094813 A1 control method and system for information delivery through mobile communications network (2002) 
35. A. Gupta, A. Kalra, D. Boston, C. Borcea, Mobisoc: a middleware for mobilesocial computing applications. Mobile Netw. Appl. 14(1), 35-52 (2009)

36. S. Smaldone, L. Han, P. Shankar, L. Iftode, in Proc. Workshop Social Netw. Syst.. BRoadspeak: enabling voice chat on roadways using vehicular social networks (2008), pp. 43-48

37. B.R. Karki, A. Hamalainen, J. Porras, in Proc. ACM/IFIP/ USENIX Middleware Conf. Companion. BSocial networking on mobile environment (2008), pp. 93-94

38. K. Pietilainen, E. Oliver, J. LeBrun, G. Varghese, C. Diot, in Proc. ACM Workshop Online Social Netw. Mobiclique: middleware for mobile social networking (2009), pp. 49-54

39. B. Molina, S.F. Pileggi, C.E. Palau, M. Esteve, Proc. Int. Workshop Use of P2P, Grid Agents Develop. A Social Framework for Content Distribution in Mobile Transient Networks (Content Netw, 2008), pp. 29-36

40. A. Papadimitriou, D. Katsaros, Y. Manolopoulos, in International Conference on e-Democracy. Social Network Analysis and its Applications in Wireless Sensor and Vehicular Networks (Next Generation Society. Technological and Legal Issues, 2009), pp. 411-420

41. Z.B. Dong, G.J. Song, K.Q. Xie, J.Y. Wang, in Proc. ACM Int. Conf. World Wide Web. An experimental study of large-scale mobile social network (2009), pp. 1175-1176

42. Sapuppo, in Proc. Wireless Conf. (EW). Spiderweb: a social mobile network (2010), pp. 475-481

43. K. Kwong, A. Chaintreau, R. Guerin, in Proc. 4th ACM Workshop Challenged Netw. Quantifying content consistency improvements through opportunistic contacts (2009). https://doi.org/10.1145/1614222.1614230

44. O. Khalid, S.U. Khan, S.A. Madani, K. Hayat, L. Wang, D. Chan, R. Ranjan, in Handbook on Data Centers. Opportunistic databank: A context-aware onthe-fly data Center for Mobile Networks (Springer-Verlag, New York, US, 2015)

45. Y. Li, D. Jin, Z. Wang, P. Hui, L. Zeng, S. Chen, Multiple Mobile data offloading through disruption tolerant networks. IEEE Trans. Mob. Comput 13(7) (June 2014)

46. A. Keränen, J. Ott, T. Kärkkäinen, in Proc. of 2nd International Conference on Simulation Tools and Techniques. The ONE simulator for DTN protocol evaluation (2009)

47. B. Yang, H. Garcia-Molina, in Proceedings 19th International Conference on Data Engineering (Cat. No.03CH37405), 5-8 March. Designing a super-peer network (2003), pp. 49-60

48. M. Adler, R. Kumar, K.W. Ross, D. Rubenstein, T. Suel, D.D. Yao, in Proceeding of 24th annual joint conference of the IEEE computer and communications societies (INFOCOM). Optimal peer selection for P2P downloading and streaming, vol 3 (2005), pp. 1538-1549

49. O. Khalid, S.U. Khan, S.A. Madani, K. Hayat, M.I. Khan, N. Min-Allah, J. Kolodziej, L. Wang, S. Zeadally, D. Chen, Comparative Study of Trust and Reputation Systems for Wireless Sensor Networks (Security and Communication Networks, 2012)

50. B. Chelly, N. Malouch, in Proc. IEEE Int. Conf. Wireless Mobile Comput. Netw. Commun.. Movement and connectivity algorithms for location-based mobile social networks (2008), pp. 190-195

51. Behrouz Jedari and Feng Xia, "A Survey on Routing and Data Dissemination in Opportunistic Mobile Social Networks," https://arxiv.org/abs/1311.0347

52. R. Cabaniss, S. Madria, G. Rush, A. Trotta, S.S. Vulli, in Proc. 11th Int. Conf. Mobile Data Manage.. Dynamic social grouping based routing in a mobile ad-hoc network (2010), pp. 295-296

53. S. loannidis and A. Chaintreau, On the strength of weak ties in mobile social networks, in proc. ACM Eurosys

54. E. Yoneki, P. Hui, S. Chan, J. Crowcroft, in Proc. ACM Symp. Model. Anal. Simul. Wireless Mobile Syst.. A socio-aware overlay for publish/ subscribe communication in delay tolerant networks (2007), pp. 225-234

55. K. Kawarabayashi, F. Nazir, H. Prendinger, in Proc. 19th Int. Conf. Comput. Commun. Netw.. Message duplication reduction in dense mobile social networks (2010). https://doi.org/10.1109/ICCCN.2010.5560124.

56. Mei, J. Stefa, in Proc. IEEE 30th Int. Conf. Distrib. Comput. Syst.. BGive2Get: Forwarding in social mobile wireless networks of selfish individuals (2010), pp. 488-497

57. S. Jain, K. Fall, R. Patra, in Proc. ACM Conf. Appl. Technol. Architect. Protocols Comput. Commun.. Routing in a delay tolerant network (2004), pp. 145-158

58. E.M. Daly, M. Haahr, The challenges of disconnected delay-tolerant manets. Ad Hoc Netw. 8(2), 241-250 (2010)

59. Boldrini, M. Conti, A. Passarella, in Proc. IEEE Int. Symp. World Wireless Mobile Multimedia Netw.. Context and resource awareness in opportunistic network data dissemination (2008). https://doi.org/10.1109/WOWMOM.2008.4594890
60. S. Ioannidis, A. Chaintreau, L. Massoulie, in Proc. IEEE Int. Conf. Comput. Commun.. Optimal and scalable distribution of content updates over a mobile social network (2009), pp. 1422-1430

61. D. Niyato, P. Wang, E. Hossain, Y. Li, in Proc. IEEE Global Commun. Conf., Miami, FL. Optimal content transmission policy in publish-subscribe mobile social networks (2010). https://doi.org/10.1109/GLOCOM.2010.5683085

62. E.M. Daly, M. Haahr, in Proc. ACM Int. Symp. Mobile Ad Hoc Netw. Comput.. Social network analysis for routing in disconnected delay-tolerant manets (2007), pp. 32-40

63. R. Akhtar, I. Memon, Z.A. Khan, C. Wang, Optimization based approach for content distribution in hybrid Mobile social networks. Optimization (2018)

64. N. Kelly, A. Antonio, Teacher peer support in social network sites. Teach Teach. Educ. (1), 138-149 (2016). Volume 56, May 2016, Pages 138-149. https://doi.org/10.1016/j.tate.2016.02.007

65. Costa et al., Socially-aware routing for publish-subscribe in delay-tolerant mobile ad hoc networks. IEEE J. Sel. Areas Commun. 26(5), 748-760 (2008)

66. K.J. Bakhsh et al., in Proceeding MobiOpp '10 Proceedings of the Second International Workshopon Mobile Opportunistic Networking. Social-greedy: a socially-based greedy routing algorithm for delay tolerant networks (2010), pp. 159-162

67. N. Bui, M. Cesana, S.A. Hosseini, et al., A survey of anticipatory mobile networking: Context-based classification, prediction methodologies, and optimization techniques. IEEE Commun. Surv. Tutorials (2017). https://doi. org/10.1109/COMST.2017.2694140

68. X. Hu, T.H.S. Chu, V.C.M. Leung, et al., A survey on mobile social networks: applications, platforms, system architectures, and future research directions. IEEE Commun. Surv. Tutorials 17(3), 1557-1581 (2015)

69. H.T. Dinh, C. Lee, D. Niyato, et al., A survey of mobile cloud computing: architecture, applications, and approaches. Wirel. Commun. Mob. Comput. 13(18), 1587-1611 (2013)

70. L. Jin, Y. Chen, T. Wang, et al., Understanding user behavior in online social networks: a survey. IEEE Commun. Mag. 51(9), 144-150 (2013)

71. M.R. Rahimi, J. Ren, C.H. Liu, et al., Mobile cloud computing: a survey, state of art and future directions. Mob. NetwAppl. 19(2), 133-143 (2014)

72. P. Bellavista, R. Montanari, S.K. Das, Mobile social networking middleware: a survey. Pervasive Mob. Comput. 9(4), 437-453 (2013)

73. K. Wei, X. Liang, K. Xu, A survey of social-aware routing protocols in delay tolerant networks: applications, taxonomy and design-related issues. IEEE Commun. Surv. Tutorials 16(1), 556-578 (2014)

74. M. Conti, S. Giordano, Mobile ad hoc networking: milestones, challenges, and new research directions. IEEE Commun. Mag. 52(1), 85-96 (2014)

75. M. Salehan, A. Negahban, Social networking on smartphones: when mobile phones become addictive. Comput. Hum. Behav. 29(6), 2632-2639 (2013)

76. X. Chen, B. Proulx, X. Gong, et al., Exploiting social ties for cooperative D2D communications: a mobile social networking case. IEEE/ACM Trans. Networking 23(5), 1471-1484 (2015)

77. W. Sherchan, S. Nepal, C. Paris, A survey of trust in social networks. ACM Comput. Surv. 45(4), 47 (2013)

78. Z. Ning, L. Liu, F. Xia, et al., CAIS: a copy adjustable incentive scheme in community-based socially aware networking. IEEE Trans. Veh. Technol. 66(4), 3406-3419 (2017)

79. L. Jennings, N. Lee, D. Shore, et al., US minority homeless youth's access to and use of mobile phones: implications for mHealth intervention design. J. Health Commun. 21(7), 725-733 (2016)

80. H. Zhou, V.C.M. Leung, C. Zhu, et al., Predicting temporal social contact patterns for data forwarding in opportunistic mobile networks. IEEE Trans. Veh. Technol. 66(11), 10372-10383 (2017)

81. Y. Zhang, L. Song, C. Jiang, et al., A social-aware framework for efficient information dissemination in wireless ad hoc networks. IEEE Commun. Mag. 55(1), 174-179 (2017)

82. F. Yu, N. Che, Z. Li, et al., in Pacific-Asia Conference on Knowledge Discovery and Data Mining. Friend recommendation considering preference coverage in location-based social networks (Springer, Cham, 2017), pp. 91-105

83. T. Wang, Y. Zhou, Y. Wang, et al., Novel opportunistic network routing based on social rank for device-todevice communication. Journal of Computer Networks and Communications Volume 2017, Article ID 2717403 , 11 pages https://doi.org/10.1155/2017/2717403

84. A. Mtibaa, A. Chaintreau, J. LeBrun, E. Oliver, A.-K. Pietilainen, C. Diot, Proc. WOSN 1st Workshop Online Social Netw.. Are you Moved by your Social Network Application, Pp. 67-72. SIGCOMM '08 ACM SIGCOMM 2008 Conference Seattle, WA, USA - August (2008), pp. 17-22 
85. S. Wasserman, K. Faust, Social network analysis: methods and applications, structural analysis in the social sciences series (Cambridge Univ. Press, Cambridge, 1994)

86. D. Saxbe, Six degrees of separation: Two new studies test 'six degrees of separation' hypothesis. Psychol. Today (2003). https://www.psychologytoday. com/us/articles/200311/six-degrees-separation

87. W. Hsu, T. Spyropoulos, K. Psounis, A. Helmy, Time Variant User Mobility in Wireless Mobile networks' IEEE INFOCOM 2007 - 26th IEEE International Conference on Computer Communications. https://doi.org/10.1109/INFCOM. 2007.94

88. S. Yang, X. Yang, C. Zhang, E. Spyrou, Using social network theory for modeling human mobility. IEEE Netw. 24(5), 6-13 (2010)

89. P. Hui, J. Crowcroft, in Proc. IEEE PerCom Workshops. How small labels create big improvements (Whiteplains, 2007), pp. 65-70

90. Y. Wu, Y. Zhu, Z. Yang, in Software engineering, artificial intelligence, networking and parallel/distributed computing (SNPD), 2017 18th IEEE/ACIS international conference on. IEEE. Routing algorithm based on ant colony optimization for mobile social network (2017), pp. 297-302

91. W.X. Zhou, D. Sornette, R.A. Hill, R.I.M. Dunbar, Discrete hierarchical organization of social group sizes. Proc. R. Soc. Lond. B Biol. Sci. 272(1561), 439-444 (2005)

92. T. Zhou, R.R. Choudhury, K. Chakrabarty, in IEEE 2009 International Conference on Computational Science and Engineering. 29-31 Aug. Diverse routing: Exploiting social behavior for routing in delaytolerant networks (2009). https://doi.org/10.1109/CSE.2009.357

93. M. Musolesi, S. Hailes, C. Mascolo, Proc. IEEE WoWMoM. Adaptive Routing for Intermittently Connected Mobile Ad Hoc Networks (Taormina-Giardini Naxos, 2005), pp. 183-189. https://doi.org/10.1109/WOWMOM.2005.17

94. A. Mtibaa, M. May, C. Diot, M. Ammar, In Proc. IEEE INFOCOM. People rank: social opportunistic forwarding (San Diego, 2010), pp. 1-5. https://doi.org/ 10.1109/INFCOM.2010.5462261

95. F. Nazir, J. Ma, A. Seneviratne, Proc. CSE. Time Critical Content Delivery Using Predictable Patterns in Mobile Social Networks (Vancouver, 2009), pp. 10661073. https://doi.org/10.1109/INFCOM.2010.5462261

96. C. Boldrini, M. Conti, A. Passarella, Exploiting users' social relations to forward data in opportunistic networks: the HiBOp solution. Pervasive Mob. Comput. 4(5), 633-657 (2008)

97. A. Shikfa, M. Onen, R. Molva, in Proc. IEEE WoWMoM. Privacy in contextbased and epidemic forwarding (2009), pp. 1-7

98. K. Graffi, P. Mukherjee, B. Menges, D. Hartung, A. Kovacevic, R. Steinmetz, in Proc. IEEE LCN. Practical security in P2P-based social networks (2009), pp. 269-272

99. R. Lu, X. Lin, X. Liang, X. Shen, A secure handshake scheme with symptomsmatching for healthcare social network. J. Mob. NetwAppl. 16(6), 683-694 (2011)

100. L. Xiaohui, L. Xu, L. Rongxing, L. Xiaodong, S. Xuemin, in Proc. IEEE GLOBECOM. An efficient and secure user revocation scheme in mobile social networks (2011), pp. 1-5

101. M. Chatterjee, G. Sivakumar, B. Menezes, in Proc. IEEEICC. Dynamic policy based model for trust based access control in P2P applications (2009), pp. 1-5

102. S. Hachem, A. Toninelli, A. Pathak, V. Issarny, in Proc. IEEE POLICY. Policybased access control in mobile social ecosystems (2011), pp. 57-64

103. L. Rongxing, L. Xiaodong, S. Xuemin, in Proc. IEEE INFOCOM. SPRING: A social-based privacy-preserving packet forwarding protocol for vehicular delay tolerant networks (2010), pp. 1-9

104. C.-M. Huang, Y.-F. Chen, S. Xu, H. Zhou, The vehicular social network (VSN)based sharing of downloaded geo data using the credit-based clustering scheme. IEEE Access 6(1), 58254-58271 (2018)

105. H. Zhou, H. Wang, X. Chen, X. Li, S. Xu, Data offloading techniques through vehicular ad hoc networks: a survey. IEEE Access 6(1), 65250-65259 (2018)

106. R. Akhtar, S. Leng, I. Memon, M. Ali, L. Zhang, Architecture of hybrid mobile social networks for efficient content delivery. Wirel. Pers. Commun. 80(1), 85-96 (2015)

107. M. Xiao, J. Wu, L. Huang, Community-aware opportunistic routing in mobile social networks. IEEE Trans. Comput. 63(7), 1682-1695 (2014)

108. J. Wu, M. Xiao, L. Huang, IEEE INFOCOM. Community Home-Based Multi-Copy Routing in Mobile Social Networks. INFOCOM, Proceedings IEE (2013). https:// doi.org/10.1109/INFCOM.2013.6567036

109. M. Xiao, J. Wu, L. Huang, Home-based zero-knowledge multi-copy routing in mobile social networks. IEEE Trans. Parallel Distrib. Syst. 26(5), 1238-1250 (2015)

110. H. Zhou, M. Ruan, C. Zhu, V.c.M. Leung, X. Shouzhi, C.-m. Huang, A timeordered aggregation model-based centrality metric for mobile social networks. IEEE Access 6(1), 25588-25599 (2018)

\section{Submit your manuscript to a SpringerOpen ${ }^{\circ}$ journal and benefit from:}

- Convenient online submission

- Rigorous peer review

- Open access: articles freely available online

- High visibility within the field

- Retaining the copyright to your article

Submit your next manuscript at $>$ springeropen.com 